\title{
Study of regime parameters of the fermenter in the production of biogas from animal liquid waste materials
}

\author{
Penka Zlateva ${ }^{1, *}$, Angel Terziev ${ }^{2}$, and Krastin Yordanov $^{1}$ \\ ${ }^{1}$ Department of Thermal Engineering, Technical University of Varna, Varna, Bulgaria \\ ${ }^{2}$ Department of Power Engineering and Power Machines, Technical University of Sofia, \\ Sofia, Bulgaria
}

\begin{abstract}
The focus of the present study is a small biogas power plant for anaerobic fermentation of several types of animal waste raw materials used for biogas production. The impact of some of the characteristics of substances such as composition, temperature, humidity, and $\mathrm{pH}$ of the mixture in the bioreactor has been considered. The above is vital for optimizing the fermentation process, and also to improve the biogas production process. The plant is located in Northeastern Bulgaria and the raw liquid manure is supplied by several neighboring small farms. The annual quantities of raw waste are as follows: cow manure - $1252 \mathrm{t} / \mathrm{a}$; chicken manure - $427 \mathrm{t} / \mathrm{a}$ and pig manure $-639 \mathrm{t} / \mathrm{a}$. The manure is collected in a preliminary tank and then pumped to the bioreactor. The fermenter itself is a hermetically sealed and thermally insulated tank where constant temperature is maintained. It is equipped with a stirring system, which helps the mixing and homogenization of the substrate. The tests were performed during three charges of the installation. The fermentation takes approximately 23 up to 25 days. The experiments were performed during the summer and autumn seasons when the ambient air temperature varies from 28 to $45^{\circ} \mathrm{C}$. The biogas can be used as an energy carried as the obtained organic fertilizer is suitable for agriculture purposes.
\end{abstract}

\section{Introduction}

Owners of small farms face the problem of manure utilization on yearly basis. One way of efficient utilization is to combine several neighboring farms and use eco-technologies that allow the extraction of biogas from manure [1]. The production of biofuels from various natural sources starts in the late 18th century and developed successfully in the 19th century. The first bioenergy plants were established in the 1940s. Manure biogas plants are most common in India, China, and Japan. Biotechnology has long been used in many European countries such as Germany, Austria, Denmark, Sweden, and others [2-3]. Due to the significant negative environmental impact because of the worldwide fast growing

\footnotetext{
*Corresponding author: pzlateva@tu-varna.bg
} 
industry and increasing energy price, it is necessary to switch to alternative sources of energy and heat production [4].

The main part of the biogas plant is the fermenters. This is the place where the wellhomogenized fertilizer mass is heated to a temperature of 30 up to $58{ }^{\circ} \mathrm{C}$. Depending on the temperature, mesophilic or thermophilic fermentation takes place. Most biogas and the highest percentage of methane gas is produced at a temperature between 45 and $55^{\circ} \mathrm{C}$. The biogas released from the fertilizer mass has a different composition depending on the percentage of dry matter, the content of carbohydrates, proteins, and the temperature of the fermentation process [5-6]. Biogas production requires maintaining the homogeneity and constant density of the substrate in the fermenters. This is done through stirrers, that prevent the formation of crust in the fermenter, which further could prevent the release of gas. It is especially important to maintain the homogenous temperature of the substrate in the fermenter. For this purpose, heat exchangers are installed on the walls and the floor, where hot water heats up the substrate.

The substrate in the fermenter, in addition to liquid and solid manure, may contain plant and animal waste, waste from slaughterhouses and dairies, distilleries and breweries, chopped straw or corn, chopped green mass, as well as many other food wastes [7]. In recent years, the produced biogas is burned in cogeneration units where both thermal and electric energy is produced. The electricity produced is used to cover the farm own needs as the rest is supplied to the network at a preferential feed in tariff. Biomass after the fermentation process is suitable for fertilization and has much better performance than ordinary manure [8-9]. Such plants are suitable for all types of farms (poultry farms, cow farms, sheep farms, pig farms, etc.). The use of biogas plants from manure has economic and social effect and leads to protection and enrichment of the environment [10-11].

Bulgaria has significant quantities of waste wood, which can be used both by direct combustion to produce heat and by gasification to produce synthetic gas. In addition, there is significant waste biomass from agriculture, which can be used for the production of biogas through fermentation plants. In the last 20 years, the focus of recovery has been large scale power plants with a capacity of 2 to $10 \mathrm{MW}$, which mainly use waste wood. In the last decade, in order to increase the energy efficiency of farms, small (local) power plants have been used for the recovery of vegetable and animal waste.

The work focuses on the experimental study of biogas production with animal and poultry manure from several neighboring farms with a small capacity of 70 cows, 6500 chickens and 350 pigs.

\section{Experimental set up}

The process of decomposition of organic substances during anaerobic fermentation is strongly influenced by the characteristics of the substances such as composition, temperature, humidity, $\mathrm{pH}$ of the medium, stirring of the sludge, etc. This requires measuring the values of temperature, humidity and $\mathrm{pH}$ of the medium in the bioreactor, using calibrated measuring instruments. The measurements were made at three charges with substrate in the fermenter.

\subsection{Preliminary set up for biogas production}

The liquid manure is collected in a receiving tank, after which it is pumped to the bioreactor via a pipeline system. The fermenter itself is a hermetically sealed and thermally insulated tank where a constant temperature is maintained. It is equipped with a stirring system to help mix and homogenize the substrates both during loading and fermentation process. The substrates are heated via water type heat exchanger. This creates the proper conditions for 
microorganisms to start decomposing organic matter during their stay in an air-free environment (anaerobic environment) and their conversion into methane $\left(\mathrm{CH}_{4}\right)$, carbon dioxide $\left(\mathrm{CO}_{2}\right)$ and organic fertilizer. The fermentation time cycle is 23 days at temperatures of 33 up to $34{ }^{\circ} \mathrm{C}$ in mesophilic mode and 53 up to $55{ }^{\circ} \mathrm{C}$ in thermophilic mode. Since the measurements were performed during the summer and autumn seasons, when the external air temperature is from $33^{\circ} \mathrm{C}$ to $43{ }^{\circ} \mathrm{C}$, no further heating of the substrate was required. The produced biogas has different concentration of methane, which depend mostly on the composition of the raw materials. As the concept of the installation was developed for the use of mainly liquid fertilizer, a methane content of about $62 \%$ can be expected.

The biogas produced by the wet fermentation method is burned in a cogeneration unit to produce simultaneous electricity and thermal energy. The heat produced is partly used for own needs and partly for heating purposes. An emergency gas flare is also installed to burn biogas during overproduction, as well as during maintenance and shutdown of the installation. The gas tank (gas storage), designed as a low pressure tank, serves for intermediate storage of biogas and to balance production fluctuations.

The substrate of the fermentation residues is separated by a solid and liquid phase separator. The liquid phase is stored intermediate in two open liquid manure storages and then exported to agricultural land. The solid phase is stored on an open paved area. Figure 1 is a representation of the proposed biogas plant.

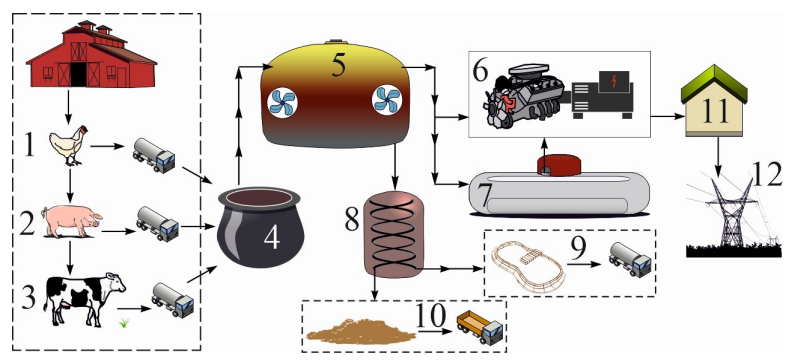

Fig. 1. Scheme of the biogas installation: 1 - poultry farm; 2 - pig farm; 3 - cow farm; 4 - receiving tank (liquid fertilizer); 5 - fermenter; 6 - cogeneration unit; 7 - gas storage; 8 - separator; 9 - liquid fertilizer; 10 - solid fertilizer; 11 - transformer; 12 - electrical network

\subsection{Raw material specifics}

The experimental studies were performed in a fermenter with the following raw waste materials: cow manure, pig manure and chicken manure. The quantities of the concerned raw waste in question are given in Table 1.

Table 1. Amount of the used inlet raw materials

\begin{tabular}{|l|c|c|c|c|}
\hline & \multicolumn{4}{|c|}{ Raw materials } \\
\hline & Animals & \multicolumn{3}{|c|}{ Substrate amount } \\
\hline & number & $\mathrm{m}[\mathrm{kg}]$ & $\mathrm{m}[\mathrm{kg} / \mathrm{d}]$ & $\mathrm{m}[\mathrm{kg} / \mathrm{a}]$ \\
\hline Cow manure & 70 & 49,00 & 3430 & 1251950 \\
\hline Chicken manure & 6500 & 0,18 & 1170 & 427050 \\
\hline Pig manure & 350 & 5,00 & 1750 & 638750 \\
\hline Total & $\mathbf{6 9 2 0}$ & $\mathbf{5 4 , 1 8}$ & $\mathbf{6 3 5 0}$ & $\mathbf{2 3 1 7 7 5 0}$ \\
\hline
\end{tabular}

The maximum quantities of raw waste for loading the fermenter are distributed and shown in Table 2. To calculate the parameters for liquid fertilizers from cows, pigs and chickens, the average dry matter content $\mathrm{CB}$ and organic dry matter content (ORS) is accepted. The results are shown in Table 2. 
Table 2. The annual amount of manures and dry matter content

\begin{tabular}{|l|c|c|c|c|c|}
\hline & \multicolumn{5}{|c|}{ Manures } \\
\hline & \multicolumn{3}{|c|}{ Raw material } & \multicolumn{2}{c|}{ Dry material } \\
\hline & {$[\mathrm{t} / \mathrm{a}]$} & {$\left[\mathrm{t} / \mathrm{m}^{3}\right]$} & {$\left[\mathrm{m}^{3} / \mathrm{d}\right]$} & TS [\% d. FM] & OTS [\% d. FM] \\
\hline Cow manure & 1252 & 1,10 & 3,12 & $10 \%$ & $8,5 \%$ \\
\hline Chicken manure & 427 & 1,10 & 1,06 & $31 \%$ & $26,35 \%$ \\
\hline Pig manure & 639 & 1,02 & 1,72 & $6 \%$ & $5,1 \%$ \\
\hline sum/average/t liquid & 2318 & 1,08 & 5,90 & - & - \\
\hline
\end{tabular}

\section{Results and Discussion}

As a result of the on-site tests performed on the fermentation process, and also the tested fertilizers from cows, pigs and chickens, the following results for biogas (methane) production were obtained, shown in Table 3.

Table 3. Biogas (methane) production from animal waste

\begin{tabular}{|l|c|c|c|c|c|}
\hline & \multicolumn{5}{|c|}{ Manures } \\
\hline & \multicolumn{3}{|c|}{ Dry material } & Methane production \\
\hline & TS [t/a] & OTS [t/a] & OTS [t/d] & {$\left[\mathrm{Nm}^{3} \mathrm{CH}_{4} / \mathrm{kgOTS}\right]$} & {$\left[\mathrm{Nm}^{3} \mathrm{CH}_{4} / \mathrm{a}\right]$} \\
\hline Cow manure & 125 & 106 & 0,29 & 0,22 & 23411 \\
\hline Chicken manure & 132 & 113 & 0,31 & 0,22 & 24756 \\
\hline Pig manure & 38 & 33 & 0,09 & 0,23 & 7493 \\
\hline $\begin{array}{l}\text { sum/average/t } \\
\text { liquid }\end{array}$ & 296 & 252 & 0,69 & 0,22 & 55660 \\
\hline
\end{tabular}

Table 4 is a representation of the total biogas production. A gas analyzer is used to determine the composition of the produced biogas. The results of the experimental study cover a period of one year.

Table 4. Total biogas production

\begin{tabular}{|l|c|c|c|}
\hline Substratum & Methane & Energy & Power \\
\hline & {$\left[\mathrm{Nm}^{3} \mathrm{CH}_{4} / \mathrm{a}\right]$} & {$[\mathrm{kWh} / \mathrm{a}]$} & {$[\mathrm{kWel}]$} \\
\hline Total animal substratum & 55660 & 556600 & 30 \\
\hline
\end{tabular}

Values of the measured characteristics from several charges of the substances of the substrates in the fermenter for 23 up to 25 days are given in Table 5 as average values of 3 measurements per day.

Table 5. Substances characteristics in the feremnter

\begin{tabular}{|c|c|c|c|c|}
\hline Fermenter & Type of the process & Temperature & Humidity & $\mathrm{pH}$ \\
\hline & & ${ }^{\circ} \mathrm{C}$ & $\%$ & \\
\hline 1 filling & Mesophilic & 33 & 75 & 6,6 \\
\hline & Thermophilic & 53 & 75 & 6,8 \\
\hline 2 filling & Mesophilic & 34 & 75 & 6,7 \\
\hline & Thermophilic & 55 & 75 & 6,9 \\
\hline 3 filling & Mesophilic & 33 & 75 & 6,6 \\
\hline & Thermophilic & 53 & 75 & 6,9 \\
\hline
\end{tabular}


The analysis of the results shows good repeatability at the measured temperature, humidity and $\mathrm{pH}$ of the medium in the bioreactor. In the mesophilic process the temperature is about $33{ }^{\circ} \mathrm{C}$, and in the thermophilic process it is about $53{ }^{\circ} \mathrm{C}$. Humidity is $75 \%$ and $\mathrm{pH} 6.6$ up to 6.9 . For all feedings, the most stable and consistent biogas production was during the retention period. Biogas production started on the 8 th day in the afternoon, gradually increasing and reaching its peak on the 15 th day. There was no production on the 20th day. This continued for several more days until 23-25 days, when there was an unexpected production of biogas. It should be noted that all three studied fermenter charges contain poultry manure, which is responsible for the production of a larger volume of biogas.

Given the amount of animal material used, the annual amount of nitrogen generated can be divided as insignificant $-156 \mathrm{~kg} /$ year.

The gas analyzer is located in the cogenerator room so that after taking into account the $\mathrm{H}_{2} \mathrm{~S}$ readings the sulfur amount can be regulated at any time by supply of air via fan. In addition, this location provides good protection from the weather and good accessibility.

\section{Conclusions}

Based on the performed experimental studies in the fermenter of the biogas power plant with anaerobic fermentation of waste raw materials from cows, chickens and pigs and their analysis, the following outputs can be summarized:

- The on-site measurements were performed for one-year period. Gas analyzer is used to define the content of the produced biogas as flowmeter is installed for the amount of the produced biogas. By using analytical relations, the amount of nitrogen generated is equal to $156 \mathrm{~kg} / \mathrm{a}$. Air fan is used to control the amount if air, and hence the total amount $\mathrm{H}_{2} \mathrm{~S}$ into the system.

- The measured substrate temperatures in the fermenter show good repeatability and the average values of the measurements in mesophilic regime is about $33{ }^{\circ} \mathrm{C}$ and about $53{ }^{\circ} \mathrm{C}$ in thermophilic regime during fermentation. The measured and averaged values of humidity and $\mathrm{pH}$ of the substrate in the fermenter during the fermentation process are $75 \%$ and 6,6 up to 6,9 , respectively;

- The annual amount of methane produced by $2318 \mathrm{t} / \mathrm{a}$ of raw material is 55660 $\mathrm{Nm}^{3} \mathrm{CH}_{4} / \mathrm{a}$. The larger is the production of methane from chicken manure 24756 $\mathrm{m}^{3} \mathrm{CH}_{4}$ / a and the lowest in pig manure $7493 \mathrm{Nm}^{3} \mathrm{CH}_{4}$ / a. Poultry manure is also responsible for the production of a larger volume of biogas;

- The obtained energy is $556600 \mathrm{kWh} / \mathrm{a}$ and is used for cover own needs and partly for heating purposes in the farms. The produced fertilizer can be successfully used for agricultural purposes.

The investigations in that paper have been implemented with the financial support of National Program "Young scientist and postdoctoral students", funded by Bulgarian Ministry of Education.

\section{References}

1. T. Al Seadi et al., Biogas Handbook (Univ. of South. Denmark Esbjerg, 2008)

2. European Commission, General and regional statistics (Eurostat Database, 2020)

3. M. Mouftahi, N. Tlili, N. Hidouri et al., Processes, 9, 48 (2021)

4. E. Sosnina, A. Shalukho, L.Veselov, Proc. of UralCon, art. no.9216233 (2020)

5. M. Temirbekova, M. Aliyarova, I. Iliev et. al., E3S Web of Conf., 180, 02019 (2020) 
6. B. G. Carp, G. Mocanu, I. Ion, F. Popescu, E3S Web of Conf., 207, 02001 (2020)

7. E. Pop, L. Mihăescu et al., IOP Conf. Ser.: Mat. Sc. Eng., 595, art. no. 012051 (2019)

8. D. Y. Damara, M. D. Dermawan, Proc. of ICT-PEP, 9249898 (2020)

9. Z. Kolev, S. Kadirova, E3S Web of Conf, 112, 01008 (2019)

10. N. Komitov, N. Shopov, V. Rasheva, E3S Web of Conf., 207, 02006 (2020)

11. G. S. Lakshmi, O. Rubanenko, G. Divya, V. Lavanya, INDISCON (2020) 